\title{
HUMANITY-CENTRED DESIGN - DEFINING THE EMERGING PARADIGM IN DESIGN EDUCATION AND PRACTICE
}

\author{
Paul RUSSELL and Lyndon BUCK \\ Buckinghamshire New University, United Kingdom
}

\begin{abstract}
Product Design has been defined by several different paradigms as it has evolved to meet the needs and desires of people and in as new ways for companies to market products to consumers. As the needs and desires of people are now increasingly met by products at all price points in consumer societies companies need to embrace a new paradigm which will enable them to differentiate their products from the competition. In addition to the need for a new differentiation strategy for marketing purposes, people are also increasingly aware of both the limited and depleting natural resources of the planet and the prevalence of inequality and poverty present in the world. A paradigm is emerging which enables companies to address all the above simultaneously. This paradigm and approach to designing products is referred to here as 'Humanity-Centred Design' in intentional reference to the 'User-Centred Design' and 'Human-Centred Design' methodologies which have been used by designers for the last 25 years. In this emerging paradigm there is a greater focus on designing products which are not only sustainable, but also actively contribute to the alleviation of poverty in all forms and promote human development and wellbeing worldwide, treating humanity as one global society. This paradigm is being taught to students of Product Design at Buckinghamshire New University to ensure that they are prepared to design products for the newest and future generations and the greatest proportion of consumers.
\end{abstract}

\section{Keywords: Human-centred design, sustainability, socially responsible design, poverty alleviation}

\section{INTRODUCTION}

A 'paradigm' can be simply defined as the collective theories, methods and values that are embraced by the majority of practitioners and practice of a discipline in a period of time which can be clearly differentiated from a period which preceded it. The concept of paradigms and of 'paradigmatic shift' as used in relation to the theory and practice of disciplines was first used by Thomas Kuhn in 1962. 'The Structure of Scientific Revolutions' [1] was specifically about developments in the natural sciences and how they significantly changed how science is undertaken. In recent years several design theoreticians have applied the concept of paradigms and paradigmatic shift to the discipline of design [2] and more specifically to consumers' expectations of products and services in developed consumer societies [3]. The paradigm described in this paper is being used to provoke students into thinking about the wider implications of the products they choose to design when undertaking the projects on the Product Design degrees at Buckinghamshire New University. Its use ensures that the students develop an understanding of their responsibility in designing a more ethical, inclusive, sustainable and humane world through their work. As this generation of students enter industry as practitioners upon graduating, they will be one of the first generation of designers to expect high levels of ethical and sustainable practice from their employers when deciding what products to design and how they will be designed. Examples of Humanity-Centred Design projects which have been undertaken by current and previous students include the design and making of cultural-specific ceramic water filters for people living in impoverished communities in different parts of the world and the design of sheet metal and ceramic cookstoves which can be fabricated using simple tools in less economically developed regions.

The value to students of defining and describing design paradigms is twofold. Firstly, from a historical perspective, the framework of paradigms shows the different values which designers needed to embody in products in order to create desirable products for consumers at different points in time and how these drivers and values relate to the context (e.g. social, political, economic, environmental, legal, etc.) which 
the consumers who purchased and used those products lived in. This gives them a holistic and wellintegrated theoretical understanding of the role of Product Design in societies and its benefit to humanity. Secondly, because projecting forward enables students to be prepared for the next paradigmatic shift by starting to address the needs and desires of the next generation of consumers by embodying their values into the products they design. By introducing them to the paradigm defined in this paper as 'Humanity-Centred Design' they are encouraged to adopt an approach to design which will meet the needs and desires of most consumers. This includes the values of functionality, aesthetics, personality, psychology, meaningfulness, usability, and environmental sustainability built up over the previous 80 years of commercial product design practice. This is augmented with a focus on the positive impacts which products can have on social sustainability and human wellbeing globally, the alleviation of poverty in all forms, and the regeneration of the natural world so that humanity can live within planetary boundaries.

\section{HOLISTIC DESIGN PRACTICE}

It is important to note that when the term 'design' is used here in reference to a paradigm and the values which define it, it is not used simply in reference to the synthesis of function, form, and meaning into a physical product. In reference to a 'design paradigm' it is used as a holistic term to cover all of the phases involved in the introduction of products into the world; from how the opportunity is identified, to defining what it needs to do and be, to how and where it will be manufactured, assembled, packaged, marketed, distributed and processed at end of life. It is increasingly being acknowledged that the more that designers are involved in this holistic manner, rather than only in the embodiment of insights and specifications into the physical product, the more impact that the application of design can have on the success of products [4][5].

\section{THE PARADIGMS OF DESIGN}

Although Product Design has existed as a distinct profession since the end of the Second Industrial Revolution ( 1914) the paradigms of Product Design (Figure 1), defined by consumer desires and delivered by companies through their designers, are typically discussed from the 1940s (post World War II) onwards [3][6]. In the earliest paradigm ( 1945-1965) products were designed and marketed based solely upon their functionality, by being able to accomplish functions which enabled people who purchased and owned them to achieve the desired outcomes. It can be said that products designed in this paradigm were 'Function Focused' [6] - that designers primarily considered what the users needed a product to do, and at what price point. Products competed in the market based primarily on their levels of efficacy, efficiency and their cost-benefit compared to competitors' products.

In the second paradigm ( 1965-1985) the role of aesthetics, and in the latter half specifically a specific sub-category of aesthetics - semantics, became additional drivers for the design of products which were appealing to consumers. Companies began to spend more effort to visually differentiate their products by targeting consumers based upon a number of variables (e.g. age, gender, and nationality), and through the use of methods which enabled consumers to understand and relate to a products' form and appearance through the use of semantics. Products designed in this paradigm can be classified as being 'Consumer Focused' [6] - designers now needed, in addition to functionality, focus on creating products which were more aesthetically and emotionally appealing to consumers.

The third paradigm ( 1986-2005) is defined by advancements in how people relate to products and communicate their identity and social status through their choice of product. Companies began to capitalise on consumers' desires to have more choice with products by offering more colour options and variants of products at different price points. Consumers were thus able to communicate both their personality - who they are and what they value - and the socio-economic position which they want to be perceived as being part of through their specific choices of products. This was further combined (from the late 1990s) with a focus on how people interact with products, both physically and psychologically. Companies saw the frustration which people had with increasingly complex and ubiquitous consumer electronics. Acknowledging that products which were cognitively taxing or hard to use were less likely to be desired and purchased, companies began to design, and market products based on how easy they were to understand and use (usability). Products in this paradigm can be defined as being 'Human Focused' [6], that their design was primarily driven by more complex human factors such as psychology and cognition. Designing products now involved providing solutions which, in addition to being functional and aesthetically appealing, enabled users to express their preferences and 
personality, and how easy they were to understand and use. The primary design methodology used in this paradigm was 'User-Centred Design' (UCD) [7] which specifically focused on what the user needs a product to do, though from a task-focused approach where users were treated as a single entity with little consideration given for differences between different people.

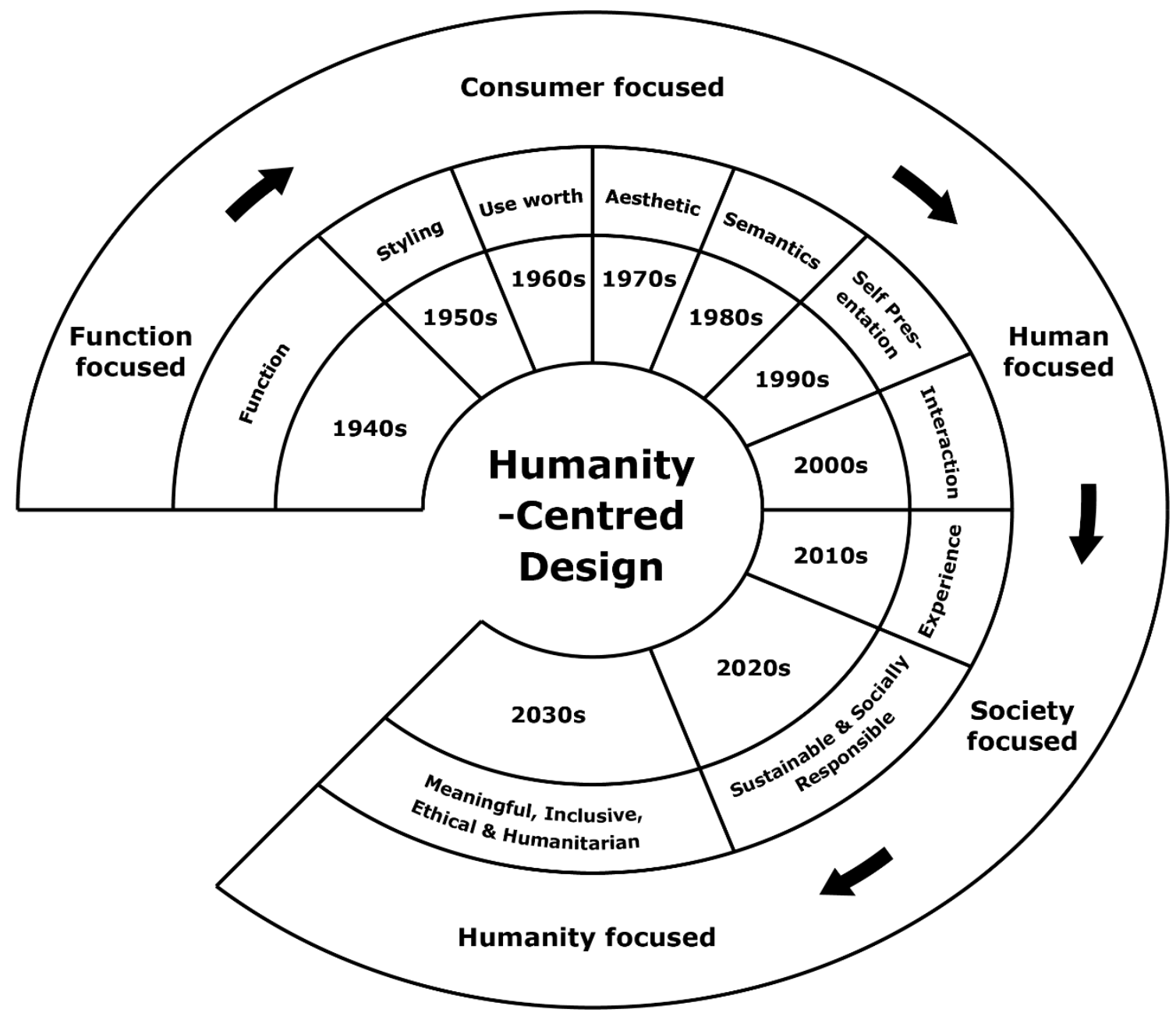

Figure 1. The Design Paradigms (outer ring) showing their values and drivers (central ring) by period in history (inner ring) (diagram by author; amended and expanded from [6])

The most recent paradigm ( 2006-2019) has been defined by designing products which appeal to consumers on a more individual level, accounting for their more specific physiological and psychological differences, and with a greater focus on products which provide 'experiences' rather than simply perform tasks or provide desired outcomes. These are further complimented with a greater focus on environmental sustainability and wider societal impacts. This new focus on the societal value and impact of designed products has been given several titles such as 'Socially Responsible Design' [8] and 'Design for Social Innovation' [9]. Products in this category could be defined as 'Society Focused' that their design is focused not only on their worth to people individually but also on the interactions between products, people and the societies in which they live. The leading design methodology used throughout this period and to date is aptly called 'Human-Centred Design' (HCD), which was first discussed in the context of Product Design in the early 2000s [10] and standardised by the International Standards Organisation in 2010 [11]. HCD is now a very well-established design methodology and has replaced UCD as the leading methodology and approach used by designers.

Companies are now looking for the next set of values and drivers which can be embodied into products by designers to differentiate them from low-cost products and generate consumer appeal to market them as premium products. Among these values are an even greater focus on environmental sustainability, and sustainability more generally - augmenting environmental sustainability with considerations for 'social sustainability', 'cultural sustainability' and with 'Sustainable Development' ("[human] development that meets the needs of the present without compromising the ability of future generations 
to meet their own needs" [12]). This yet to be fully formed or defined paradigm currently lacks a universally adopted name - but is being proposed here as 'Humanity-Centred Design' in reference to the major design methodologies which have been widely used for the last $\sim 25$ years.

\section{HUMANITY-CENTRED DESIGN VALUES AND DRIVERS}

The UCD methodology encourages designers to consider all elements of Human Factors (such as ergonomics, cognition, psychology) when designing products to ensure high levels of usability and productivity. HCD built on UCD principles by further encouraging designers to focus also on "human well-being, user satisfaction, accessibility and sustainability" when designing products [11]. A proposal of the drivers which will define the 'Humanity-Centred Design' methodology being described here can be found in research by Philips Design which is presented in 'Innovation Design - Creating Value for People, Organizations and Society' by Elke den Ouden which discusses the historical and emerging paradigms of design through the perspective of the values which products embody [3]. den Ouden describes the next paradigm which will emerge as the "Transformation Economy" and the key values which designers will need to embody into products in order for them to be appealing to consumers to include that they will need to be "meaningful", "inclusive" and "ethical", and require "empathy" and "cooperation" [3] in order to be successful.

For products to be 'meaningful' they will need to be at the forefront of the 'reflective' emotional drivers identified by Don Norman [13]. This generation of products will need to have significant meaning beyond their ownership and use, and beyond the owner and user. Several examples of products that would meet this level of meaningfulness have been introduced to the market over the last decade. One method of achieving this is the 'Buy One Give One' approach where if a consumer purchases a product then another product (either the same product or a cost-reduced version) is donated to someone who could otherwise never have attained it due to poverty, for example TOMS shoes donate one pair of shoes for every one purchased [14]. Although this model is criticised from a humanitarian development perspective, because it undermines local shoe making companies in the areas where the shoes are donated, a more appropriate version of the model where the shoes are purchased through local companies could be developed which resolves this. In this way, the level of meaning which a product embodies has another level - that through your purchase and product use you have not only satisfied your own needs, wants and desires, but the genuine needs of someone else also.

In order for products to be 'inclusive' they will need, first and foremost, to be designed in adherence with Universal Design Principles [15] in order to ensure that people of all genders and ages, and the greatest extent of physiological and psychological abilities can use them equally. Designers also need to consider how they can provide product variants at different price points so that people of different income levels can buy and benefit from their products - something which many companies that previously refused to have now found that both they and consumers benefit from (e.g. Apple's iPhone $\mathrm{C}$ and SE series of lower cost phones). Furthermore, products designed with a Humanity-Centred focus will need to be properly considered from a cultural perspective - both functionally and aesthetically. In terms of function, it is important that companies looking to introduce products globally acknowledge long-held culturally specific tools and methods of accomplishing outcomes and do not introduce products which undermine them and impose a foreign, typically Western (European and North American), ways of doing and being. Imposing new tools and ways of doing things which are alien to the population in question is arguably a form of neo-imperialism [16] and does not respect and ensure the retention of the different cultural groups present in the world. In terms of aesthetics, many companies are already trying to ensure the cultural appropriateness of products via aesthetics where possible through product variants. However, when doing this it is important that attempts to culturally appropriate products are neither a gross simplification of cultural difference (e.g. sticking a flag on the product, or some text in the local language) or outright offensive due to insufficient research or understanding. For example, Amazon were forced to remove doormats with religious imagery on from their website which people found offensive because it meant walking on them which was considered disrespectful [17]. While the designer may have felt this was a suitable method to make the product appeal to different cultural groups, they in fact did the reverse and offended potential consumers.

In order for products to be 'ethical' they need to go beyond being simply 'sustainable', if that is taken to mean only 'able to be sustained'; they must be carbon neutral at minimum, ideally in line with circular economy principles, or even be carbon positive where possible. A good example of a company which takes extensive effort to offset the environmental impact of their products is WeWood which makes 
wooden watch bodies and plants a tree for every watch which they sell [18]. In addition to offsetting the carbon footprint of their products they also enable a 'reflective' element to their products for their consumers so the benefit, in terms of being 'Humanity-Centred', is twofold.

Products must also be socially sustainable to be considered ethical. Social sustainability refers to all the variables involved with the creation of a product that relates to human wellbeing. So, for example, to be considered 'Humanity-Centred' products would need to be free of any forms of human exploitation in the selection of materials at any point of their extraction, transport or processing, in the manufacture of components, and in the assembly of components into end products. Better still, where extraction, processing, production and assembly are to be undertaken by populations living at or close to survival levels of financial income, the purposeful choice of companies which pay better than the bare minimum to undertake these stages of the design and manufacture of products over companies which only pay the bare minimum is advisable.

Finally, consideration for the design of ethical products includes, importantly, how they will be advertised and marketed. An example which caused significant controversy in the past year is the marketing and advertising of Juul's e-cigarettes. If the product is considered in isolation it could be argued that it is a 'Humanity-Centred' product because it contributes positively to human wellbeing via encouraging people to switch to a healthier alternative than smoking tobacco, which results in a reduction of ill-health and death. However, when considering how the product was advertised and marketed in addition to the physical product itself, the design of the product (in the holistic sense aforementioned) quickly becomes unethical and hence cannot be considered to be a 'Humanity-Centred' product. Juul has been criticised for using young, teenage-looking, people in all of their early advertisement, and also for their extensive use of social media platforms to market their products which are predominantly used by young people [19]. Thus, the fact that their e-cigarette is very popular among people too young to legally use them is arguably not an accidental outcome, but an intentional and unethical decision, hence it cannot be 'Humanity-Centred'.

\section{THE DEMAND FOR HUMANITY-CENTRED DESIGN}

People belonging to 'Generation Z' are now aged between roughly 10 and 25 years old and have, in 2019, surpassed 'Millennials' as the largest proportion of consumers in the world. Research shows that personal expenditure on products and services rises consistently from the age of 18 and peaks between the ages of 45 and 54 before decreasing [20]. That means that between now and 2050 people from Generation $\mathrm{Z}$ will make up the majority of consumers and the largest proportion of spending influence so their specific needs, desires and values will define the products and services which companies must create in order to succeed. Research into the values and drivers of Generation $\mathrm{Z}$ consumers has shown that they place high levels of importance on the "ethics, practices and social impact" [21] of companies when selecting which to purchase products and services from and do not solely base their choices on the quality of products or services themselves [21]. More specifically, to design products which are appealing to the next generation of consumers, companies will need to "highlight their efforts to be good global citizens" and "must demonstrate their commitment to a broader set of societal challenges, such as sustainability, climate change and hunger" at the "front and centre of their brand" [21]. Thus, consumer expectations for companies to deliver on their social responsibility is evolving into an expectation that they focus on their responsibility globally, and that they show concern for human wellbeing in all parts of the world as an interconnected, global society. These values will drive the approach to designing products from this generation onwards so companies and their designers will need to start capitalising on them now to satisfy the needs and desires of consumers for the foreseeable future.

\section{CONCLUSIONS}

Consumer research shows that people are willing to pay more for products which contribute to the alleviation of poverty in the wider world and to reducing and reversing the destruction of the planet. This is increasingly true with the emergence of Generation $\mathrm{Z}$ as the largest proportion of consumers. Thus, companies and their designers must now start to embody these values and ethics into their products to ensure that they are appealing to consumers in emerging paradigm. This paper has proposed a title for this emerging paradigm and the values which need to be embodied into this new approach. The proposal builds upon the work of a number of other researchers who have published in the area of design paradigms and is further informed by the research being undertaken by the primary author into the design of products which contribute to the alleviation of poverty in regions where even basic human needs are 
not met satisfactorily. The work presented in this paper will be further developed into a set of structured guidelines in the form of cards which can be used to inform and nudge students', designers' and codesigners' decision making at all stages of the design process from research and inspiration, through to brainstorming of new product ideas, product development, and up to how products will be marketed and advertised.

\section{ACKNOWLEDGEMENTS}

The research presented in this paper has been funded by the European Union's Horizon 2020 research and innovation programme under grant agreement number 820718 and is jointly funded by the European Commission and the Department of Science and Technology of India (DST).

\section{REFERENCES}

[1] Kuhn T. The Structure of Scientific Revolutions, 1962.

[2] Crilly N. The Structure of Design Revolutions: Kuhnian Paradigm Shifts in Creative Problem Solving. Design Issues, 2010, 26-1, 54-66.

[3] den Ouden E. Innovation Design - Creating Value for People, Organizations and Society, 2012. Springer International.

[4] Roper S. et al. The roles and effectiveness of design in new product development: A study of Irish manufacturers, 2016. Research Policy, 2016, 45-1.

[5] Gonzalez S. When's the right time to involve design? 2019. Available: www.invisionapp.com/inside-design/right-time-for-design/ [Accessed on 2020, 29 January]

[6] Zhang T. and Dong H. Human-Centred Design: An Emergent Conceptual Model. In Include2009, Royal College of Art, London, April 2009.

[7] Norman D. \& Draper S. User-Centred System Design: New Perspectives on Human-Computer Interaction, 1986 (CRC Press).

[8] Gavin M., de Vere I., \& Misic V. Socially responsible design: thinking beyond the triple bottom line to socially responsive and sustainable product design. CoDesign, 2011, 7:3-4, 143-154.

[9] Manzini E. Design, When Everybody Designs: An Introduction to Design for Social Innovation, 2015. MIT Press.

[10] Buchanan R. Human dignity and human rights: Thoughts on the principles of human-centred design. Design issues, 2010, 17(3), 35-39.

[11] International Standards Organization. Human-centred design. ISO 9241-210:2010(E).

[12] World Commission on Environment and Development. Our Common Future: World Commission on Environment and Development, 1987. Oxford: Oxford University Press.

[13] Norman D. Emotional Design: Why We Love (or Hate) Everyday Things, 2007. ProQuest Ebook Central: Basic Books.

[14] TOMS. TOMS 2019 Global Impact Report, 2019.

[15] Burgstahler S. Universal Design: Process, Principles, and Applications, n.d. College of Engineering, University of Washington.

[16] Nussbaum, B. Is Humanitarian Design the New Imperialism? 2010. Available: www.fastcompany.com/1661859/is-humanitarian-design-the-new-imperialism [Accessed on 2020, 29 January]

[17] Bose A. Amazon Removes Doormats with Images of Hindu Gods After Protests and Call for Boycott, 2016. Huffington Post. Available: www.huffingtonpost.in/2016/06/06/amazon-hindugods_n_10316708.html [Accessed on 2020, 29 January]

[18] WeWood. A Tree Story. Available: www.we-wood.com/a-tree-story [Accessed on 2020, 28 February]

[19] Chaykowski K. The Disturbing Focus of Juul's Early Marketing Campaigns, 2018. Forbes. Available: https://bit.ly/3bKOSRr [Accessed on 2020, 27 March]

[20] Paulson B. How a 'Youth Boom' Could Shake Up Spending Trends, 2019. Available: www.morganstanley.com/ideas/gen-z-millennials-set-for-consumer-spending-increases [Accessed on 2020, 29 January]

[21] Deloitte. Welcome to Generation Z, 2019. 